\title{
Mapeamento e avaliação dos serviços ecossistêmicos entre 1985 e 2019 na sub- bacia hidrográfica do Arroio Passo Fundo (Guaíba/RS)
}

\author{
Mapping and assessment of ecosystem services between 1985 and 2019 in \\ the Arroio Passo Fundo watershed (Guaíba / RS)
}

\author{
Sumirê da Silva Hinata 1 \\ Luis Alberto Basso 2 (10) \\ José Gomes dos Santos ${ }^{3}$ [다
}

\begin{abstract}
Palavras-chave:
Classes de cobertura e uso do

solo

Projeto MapBiomas

Dinamica EGO

Função ecossistêmica

Cenários futuros

Resumo

O objetivo principal deste estudo consiste em analisar os Serviços Ecossistêmicos fornecidos na Sub-Bacia Hidrográfica do Arroio Passo Fundo, localizada no município de Guaíba/RS. Para analisar as transições ocorridas nas classes de uso e cobertura do solo no intervalo de tempo compreendido entre 1985 e 2019 foram utilizados os dados da Coleção 5 do Projeto MapBiomas, bem como as transformações ocorridas nesse intervalo de 34 anos, que subsidiaram a elaboração de um cenário tendencial para os anos de 2030 e 2050, através do software livre Dinamica EGO. Os resultados mostram que a sub-bacia forneceu em torno de US\$21.020.441 em Serviços Ecossistêmicos em 1985, com diminuição para US\$19.635.767 em 2019, e um valor estimado em US\$19.059.616 no cenário tendencial de 2050. A alteração mais evidente foi a conversão de áreas de Formação campestre para o cultivo de soja. A identificação das classes de uso e cobertura do solo associadas aos múltiplos Serviços Ecossistêmicos é uma alternativa eficaz para que gestores públicos e tomadores de decisão elaborem estratégias, proativas e eficientes, para melhoria da qualidade ambiental da sub-bacia.
\end{abstract}

\section{Keywords:}

LULC classification

MapBiomas Project

Dinamica EGO

Ecosystem function

Scenarios for land use

\begin{abstract}
This article analyzes the Ecosystem Services provided in the Arroio Passo Fundo watershed, located in Guaíba City/RS. To analyze the transitions that occurred in land use and land cover classes between 1985 and 2019, MapBiomas Collection 5 Project data were used, as well as the transformations that occurred in this interval of 34 years, which supported the elaboration trend scenario for 2030 and 2050, through the free software Dinamica EGO. The results show that watershed provided around US\$ $21,020,441$ in Ecosystem Services in 1985 , decreasing to US $\$ 19,635,767$ in 2019 , and an estimated value of US $\$ 19,059,616$ in the 2050 trend scenario. The most evident change was the conversion of grassland to soy bean cultivation. The identification of land use and land cover classification associated with multiple Ecosystem Services is an effective alternative for public managers and decision makers to develop proactive and efficient strategies for improving the environmental quality in the watershed.
\end{abstract}




\section{INTRODUÇÃO}

A avaliação ambiental considerando os Serviços Ecossistêmicos (SE) é uma abordagem inovadora e em expansão em muitos países, ainda incipiente no Brasil. Os SE são as características, funções ou processos ecológicos que contribuem direta ou indiretamente para o bem-estar humano, ou seja, os benefícios que as pessoas obtêm do funcionamento dos ecossistemas (COSTANZA et al., 1997, 2017; MAES et al., 2012, 2013; MEA, 2005) e incluem ecossistemas naturais e modificados pela ação antrópica como fonte de recursos de SE.

A classificação dos SE associada ao uso e cobertura do solo na sub-bacia hidrográfica do Arroio Passo Fundo (SBHAPF) utilizou como base a Coleção 5 do Projeto Mapbiomas (2020), onde foram observadas as variações entre o ano de 1985 e 2019. Com base nessas transições ocorridas no intervalo de 34 anos, foi possível simular o cenário tendencial para os anos de 2030 e 2050, através do software livre Dinamica EGO 5.0 (2020) que permite a avaliação de questões ambientais através da composição de um modelo de simulação espacialmente explícito, possibilitando a evolução de diferentes cenários com base na situação ambiental (RODRIGUES; SOARES-FILHO; COSTA, 2007) - O ano de 2030 foi selecionado por ser o horizonte para os 17 Objetivos de Desenvolvimento Sustentável no Brasil da Organização das Nações Unidas (ONU), especialmente o Objetivo 15 - Vida terrestre que visa "Proteger, recuperar e promover o uso sustentável dos ecossistemas terrestres, gerir de forma sustentável as florestas, combater a desertificação, deter e reverter a degradação da terra e deter a perda de biodiversidade", e 2050 por ser referência para a Avaliação Ecossistêmica do Milênio (MEA, 2005).

O Dinamica EGO permite estimar as mudanças de uso e ocupação do solo no intervalo dos próximos 34 anos, e correlacionar às alterações nos SE na SBHAPF, sendo esta abordagem empregada em outros trabalhos de alteração de uso e cobertura do solo correlacionadas aos SE (BACHI et al., 2020; WOLDEYOHANNES et al., 2020).

Utilizar os SE como indicadores de alteração da qualidade ambiental, com base em dados de uso e cobertura do solo, pode ser uma importante ferramenta para subsidiar políticas públicas e auxiliar gestores para monitorar a SBHAPF, bem como qualquer outra região que disponha de mapeamento.

\section{Área de estudo}

A SBHAPF localiza-se entre as coordenadas geográficas $30^{\circ} 07^{\prime} 17^{\prime \prime S}, 30^{\circ} 12^{\prime} 09^{\prime \prime S}, 51^{\circ} 18^{\prime} 28^{\prime \prime} \mathrm{W}$ e $5129^{\prime} 24^{\prime \prime}$ W (Figura 1), e está localizada em toda sua extensão no município de Guaíba/RS. Com uma área de aproximadamente $75,7 \mathrm{~km}^{2}$ (DRH/SEMA, 2016) inserida no Bioma Pampa, a SBHAPF limita-se a leste pelo Lago Guaíba e está inserida na Bacia Hidrográfica do Lago Guaíba.

Figura 1 - Mapa de situação e localização geográfica da SBHAPF.

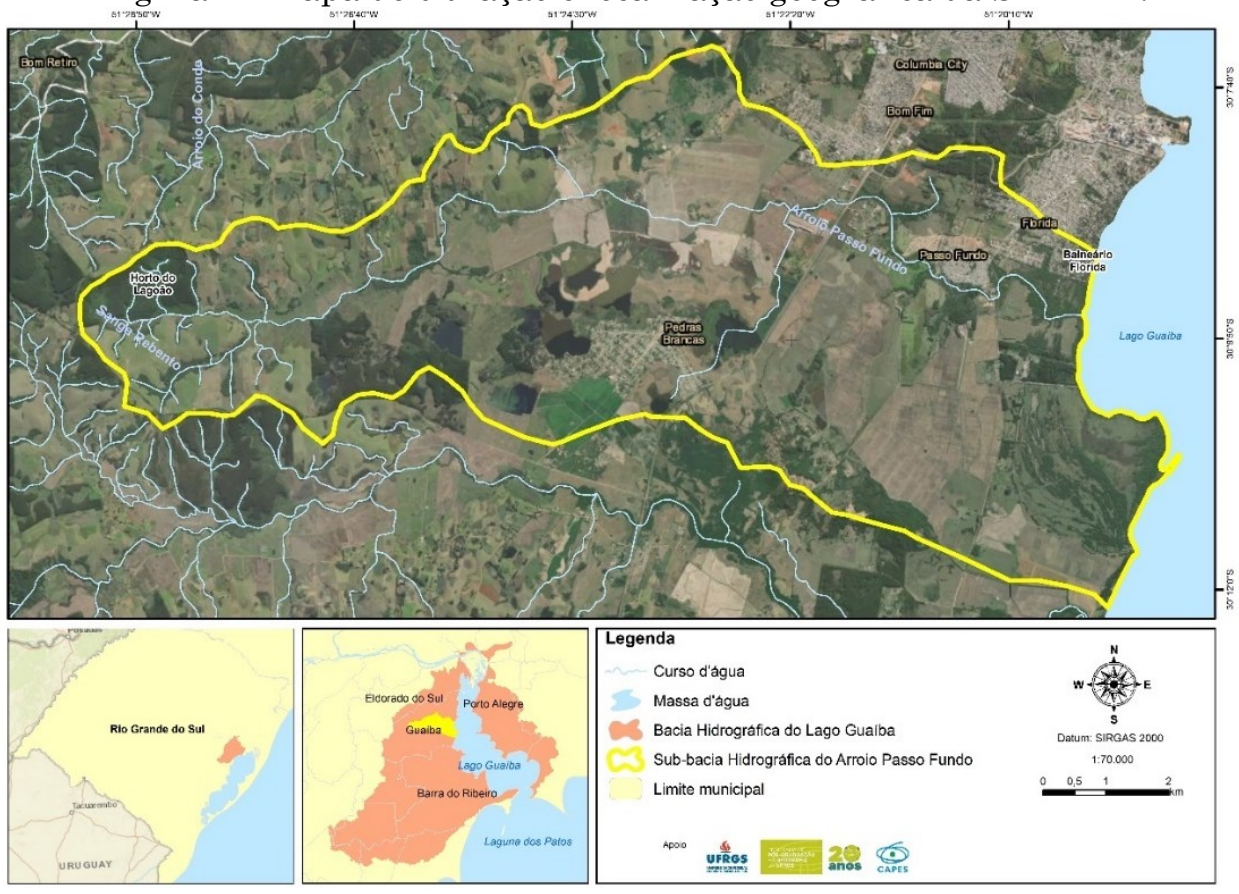

Fonte: Elaborado pelos autores (2021). 
Em relação às nascentes do Arroio Passo Fundo há o predomínio de área rural no entorno e presença de áreas de silvicultura. As áreas destinadas a agropecuária próximas ao curso médio, observadas em 2002, continuam sendo exploradas por este uso: se antes foi relatada a presença de barragens ilegais e ausência de mata ciliar e consequente erosão em Área de
Preservação Permanente (APP) ao longo do Arroio Passo Fundo (GUERRA et al., 2002), atualmente a degradação permanece, incluindo relatos de atividade industrial com despejo irregular de produtos químicos (Figura 2), que tem agravado a situação de poluição do curso d'água a jusante e trazido sérias consequências à saúde da população.

Figura 2 - Trecho do APF (Guaíba/RS) comprometido pelo despejo irregular da atividade industrial (Coordenadas geográficas $30^{\circ} 09^{\prime} 29 ”$ 'S, $51^{\circ} 20^{\prime} 19^{\prime \prime} \mathrm{W}$ ).

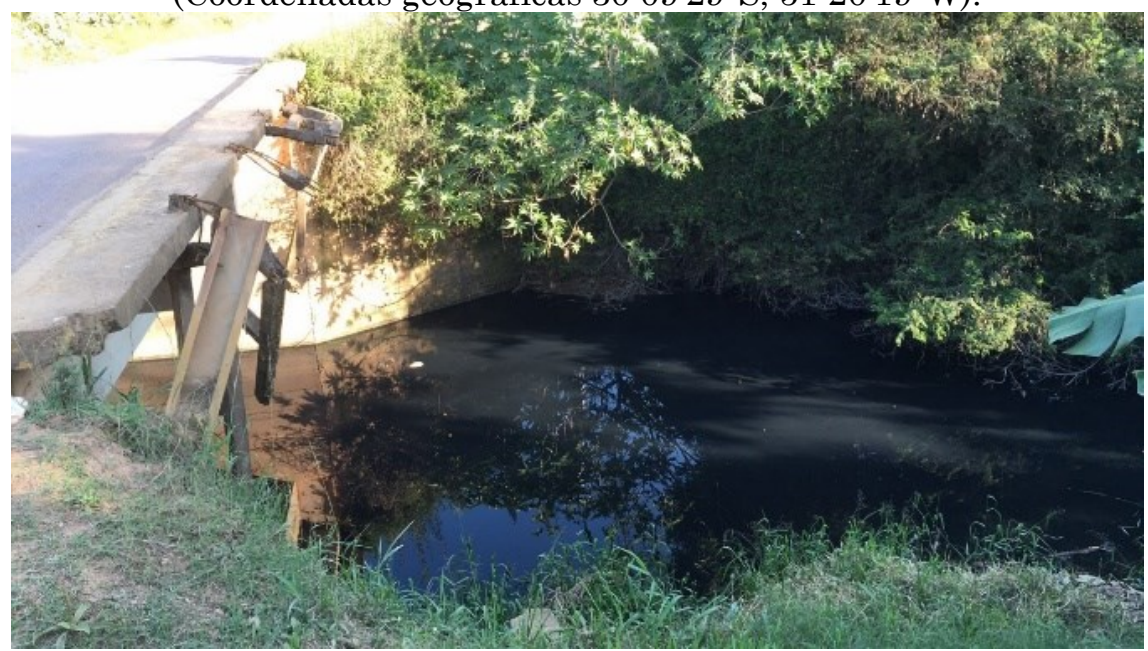

Fonte: os autores (2019).

A SBHAPF possui elevado potencial para atividades voltadas à recreação, ao turismo, às atividades culturais, esportivas e de observação da paisagem, especialmente na área denominada Balneário Florida (Guaíba/RS) na porção nordeste da sub-bacia (Figura 1) junto à orla do Lago Guaíba (Figura 3).

Figura 3 - Balneário Florida (Guaíba/RS) destinada ao turismo e recreação de moradores e visitantes (Coordenadas geográficas $30^{\circ} 09^{\prime} 15^{\prime} \mathrm{S}, 51^{\circ} 19^{\prime} 20^{\prime} \mathrm{W}$ ).

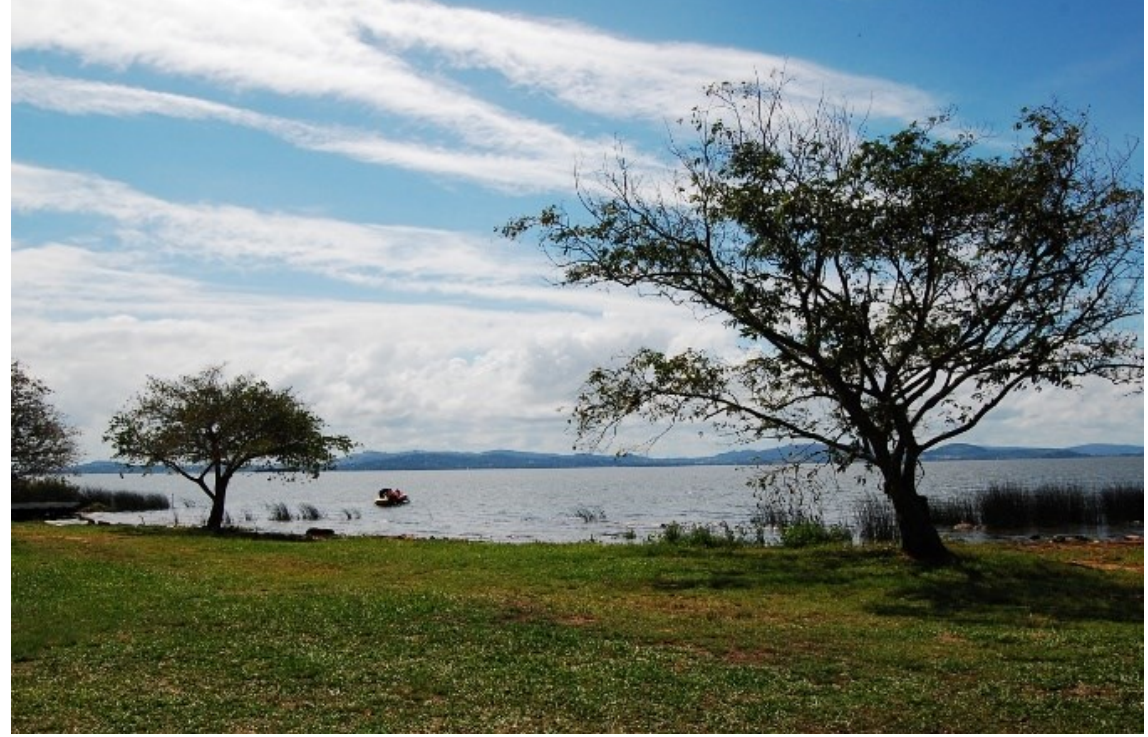

Fonte: os autores (2019). 


\section{MATERIAIS E MÉTODOS}

Os dados utilizados para o mapeamento da área de estudo são provenientes da Coleção 5 do Projeto de Mapeamento Anual da Cobertura e Uso do Solo do Brasil (MapBiomas), que gerou uma série histórica de mapas anuais produzidos a partir da classificação pixel a pixel de imagens de satélites da série Landsat com resolução de 30 metros (MAPBIOMAS, 2020).

\section{Serviços Ecossistêmicos (SE)}

O conceito de SE tem sido discutido desde que adquiriu maior relevância e passou a estar presente em muitas publicações após 1997. Os problemas relacionados a mudanças nestes serviços afetam o bem-estar humano de várias formas. Os componentes do bem-estar, vividos e percebidos pelas pessoas, são dependentes da situação, refletindo a geografia local, a cultura e as circunstâncias ecológicas (MEA, 2005).

Os serviços ecossistêmicos não estão ligados exclusivamente às atividades humanas relacionadas à natureza, mas envolvem aspectos voltados ao desenvolvimento socioeconômico, porque esses serviços são a base para que os ecossistemas naturais e as espécies a ele vinculadas possam sustentar e preencher a vida humana.

O desconhecimento do tema relacionado ao fornecimento de bens e serviços providos pelos ecossistemas induz a sociedade e os gestores públicos de maneira geral à negligência. Estimase que haja uma valoração dos serviços ecossistêmicos à medida que os impactos de ações humanas sobre o meio ambiente se intensifiquem, e os custos e investimento em tecnologias se tornem mais aparentes. Os SE são absolutamente essenciais à civilização, mas a vida urbana moderna torna obscura sua existência (DAILY, 1997).

Nas últimas décadas estudos se propuseram a estimar o valor de uma ampla variedade de SE. Costanza et al. (1997) foram precursores ao apresentar o valor dos serviços ecossistêmicos no planeta e estimar valores para os SE por unidade de área por bioma. Além desse estudo, uma pluralidade de outros trabalhos se dedicam ao tema nos mais distintos lugares (BAGSTAD; SEMMENS; WINTHROP, 2013; CABRAL et al., 2016; DE LIMA et al., 2018; HERNÁNDEZBLANCO et al., 2020; LEITÃO; SANTOS; ARAGÃO, 2017; MAES et al., 2013; MARTINEZ-HARMS et al., 2017) .

A categorização proposta por Costanza et al. (2017) faz uma abordagem integradora, relacionando o capital natural, social, construído e humano necessário para produzir esses serviços, e considera: a) Serviços de provisão ou abastecimento; b) Serviços de regulação; c) Serviços culturais; e d) Serviços de suporte, os quais foram agrupados em 17 principais categorias.

A importância do trabalho de Costanza et al. (1997) resultou na estimativa do valor total global da extensão dos serviços ecossistêmicos e no esquema de classificação com essas categorias principais que representam o uso global da terra. À época, os autores estimaram que os ecossistemas fornecem pelo menos US\$ 33 trilhões em serviços anualmente ao planeta, e concluíram que os SE fornecem uma parcela importante da contribuição total para o bem-estar humano.

A adoção de valores monetários para avaliação de SE pode induzir a uma interpretação negativa quanto à monetização da natureza, mas Kubiszewski et al. (2017) sustentam que a avaliação dos SE em unidades monetárias não está em conflito com outras abordagens ao considerar sua importância, mas representa uma informação adicional que pode complementar outras abordagens.

Valorar os serviços ecossistêmicos não é a mesma coisa que mercantilizá-los para o comércio em mercados privados. A maioria dos serviços ecossistêmicos traduz-se em bens públicos, o que significa que a privatização e os mercados convencionais funcionam mal, se é que funcionam. No entanto, conhecer o valor dos serviços ecossistêmicos é útil para sua gestão eficaz, que em alguns casos pode incluir incentivos econômicos, como aqueles usados no sistema de Pagamento por Serviços Ambientais (PSA) bem-sucedido da Costa Rica (COSTANZA, 2006).

\section{Observação e projeção do uso e cobertura do solo}

As alterações de uso e cobertura do solo foram analisadas com base no limite da SBHAPF, sendo 1985 o ano mais antigo e 2019 o mais recente disponibilizados pelo Projeto MapBiomas. Esses arquivos, disponíveis em formato raster, foram convertidos em shapefile no software ArcGis 10.5, onde foram calculadas as áreas de cada polígono das classes de uso e cobertura do solo.

A SBHAPF se encontra inteiramente inserida no Bioma Pampa e compreende as classes Floresta Natural (Formação Florestal); Floresta Plantada; Campo Alagado e Área Pantanosa; Formação Campestre; Infraestrutura Urbana; Outras Áreas não 
Vegetadas; Outras Lavouras Temporárias; Soja; e Corpos d'água (Rios e Lagos).

Os cenários tendenciais para 2030 e 2050 foram simulados no software Dinamica EGO (SOARES-FILHO; RODRIGUES; COSTA, 2009), que permite a modelagem de mudanças ambientais através da investigação de trajetórias de paisagens e dinâmica de fenômenos espaciais. Os modelos de simulação espacialmente explícitos permitem identificar causas e processos que atuam sobre os sistemas ambientais, e consequentemente verificar como ocorre a evolução em diferentes cenários, considerando variáveis socioeconômicas, políticas e ambientais (RODRIGUES; SOARESFILHO; COSTA, 2007).

O Dinamica EGO usa um método de inferência estatística para estimar a probabilidade de conversão entre as categorias de uso e cobertura do solo sob um conjunto de variáveis explicativas e observações de mudanças de uso e cobertura do solo anteriores, enquanto os padrões espaciais da mudança de categorias de uso e cobertura do solo são produzidos pelo princípio de funcionamento que governa autômatos celulares (WOLDEYOHANNES et al., 2020). Os autômatos celulares são sistemas espaciais dinâmicos, que têm por base a ideia de que o estado de uma célula (pixel) da matriz depende do estado prévio das células que se encontram dentro de uma determinada vizinhança, de acordo com um conjunto de regras de transição (ROCHA, 2012).

A abordagem pelos autômatos celulares permite aos usuários definir ou editar parâmetros para controlar o tamanho médio e a variância da mancha (patch) que conduzem a transição das classes de uso e cobertura do solo, podendo ser convertido de uma abordagem puramente automática para uma abordagem orientada por tendências (WOLDEYOHANNES et al., 2020).

Neste estudo, além dos mapas do ano inicial (1985) e final (2019), foram incorporados os mapas de hipsometria, declividade, litologia e geologia, necessários para que o modelo pudesse calcular os pesos de evidência para produzir o mapa de probabilidades de transição. Não foram incorporados ao modelo variáveis socioeconômicas, políticas e ambientais, assumindo-se que a sub-bacia será alterada sem influência de fatores exógenos.

De posse dos dados das áreas calculadas para os anos de 1985 e 2019, e dos cenários tendenciais de 2030 e 2050, as classes de uso e cobertura foram correlacionadas aos SE seguindo os valores propostos por Costanza et al. (1997).

\section{RESULTADOS E DISCUSSÃO}

\section{Uso e cobertura do solo observado e projetado na sub-bacia do $A P F$}

A sub-bacia do APF apresentou nove tipos de classes de uso e cobertura do solo que se transformaram significativamente de 1985 até 2019 (Tabela 1 e Figura 4).

Tabela 1 - Uso e cobertura do solo na sub-bacia do APF observado (1985 e 2019) e tendencial (2030 e 2050).

\begin{tabular}{|c|c|c|c|c|c|c|c|c|c|c|c|c|}
\hline \multirow{2}{*}{$\begin{array}{l}\text { Classes de uso e } \\
\text { cobertura do solo }\end{array}$} & \multicolumn{8}{|c|}{ Área $\left(\mathbf{k m}^{2}\right)$} & \multicolumn{4}{|c|}{ Mudanças } \\
\hline & 1985 & $\%$ & 2019 & $\%$ & 2030 & $\%$ & 2050 & $\%$ & $\begin{array}{c}19852 \\
019\end{array}$ & $\begin{array}{c}20192 \\
030\end{array}$ & $\begin{array}{c}19852 \\
050\end{array}$ & $\begin{array}{c}20192 \\
050\end{array}$ \\
\hline $\begin{array}{l}\text { Campo Alagado e } \\
\text { Área Pantanosa }\end{array}$ & 0,12 & 0,16 & 0,13 & 0,17 & 0,12 & 0,16 & 0,12 & 0,16 & 0,00 & $-0,01$ & 0,00 & $-0,01$ \\
\hline Floresta Natural & 15,25 & 20,14 & 18,10 & 23,91 & 18,32 & 24,20 & 17,84 & 23,57 & 2,86 & 0,22 & 2,60 & $-0,26$ \\
\hline Floresta Plantada & 1,92 & 2,53 & 3,91 & 5,16 & 4,45 & 5,88 & 5,48 & 7,24 & 1,99 & 0,54 & 3,57 & 1,58 \\
\hline $\begin{array}{l}\text { Formação } \\
\text { Campestre }\end{array}$ & 24,51 & 32,38 & 17,54 & 23,16 & 4,15 & 5,48 & 2,88 & 3,81 & $-6,98$ & $-13,39$ & $-21,63$ & $-14,65$ \\
\hline $\begin{array}{l}\text { Infraestrutura } \\
\text { Urbana }\end{array}$ & 0,64 & 0,85 & 3,29 & 4,35 & 3,60 & 4,76 & 3,84 & 5,07 & 2,65 & 0,31 & 3,20 & 0,55 \\
\hline $\begin{array}{l}\text { Outras Áreas Não } \\
\text { Vegetadas }\end{array}$ & 2,00 & 2,64 & 0,72 & 0,95 & 0,51 & 0,67 & 0,29 & 0,38 & $-1,28$ & $-0,21$ & $-1,71$ & $-0,43$ \\
\hline $\begin{array}{l}\text { Outras Lavouras } \\
\text { Temporárias }\end{array}$ & 26,47 & 34,97 & 25,70 & 33,94 & 26,48 & 34,98 & 27,12 & 35,82 & $-0,78$ & 0,78 & 0,64 & 1,42 \\
\hline Soja & 0,00 & 0,00 & 2,75 & 3,64 & 14,46 & 19,10 & 14,51 & 19,17 & 2,75 & 11,71 & 14,51 & 11,76 \\
\hline Rios e Lagos & 4,80 & 6,33 & 3,57 & 4,72 & 3,61 & 4,77 & 3,61 & 4,77 & $-1,22$ & 0,04 & $-1,18$ & 0,04 \\
\hline Total Geral & 75,71 & 100 & 75,70 & 100 & 75,70 & 100 & 75,70 & 100 & - & - & - & - \\
\hline
\end{tabular}


Figura 4 - Mapeamento do uso e cobertura do solo na SBHAPF observado (1985 e 2019) e tendencial (2030 e 2050).

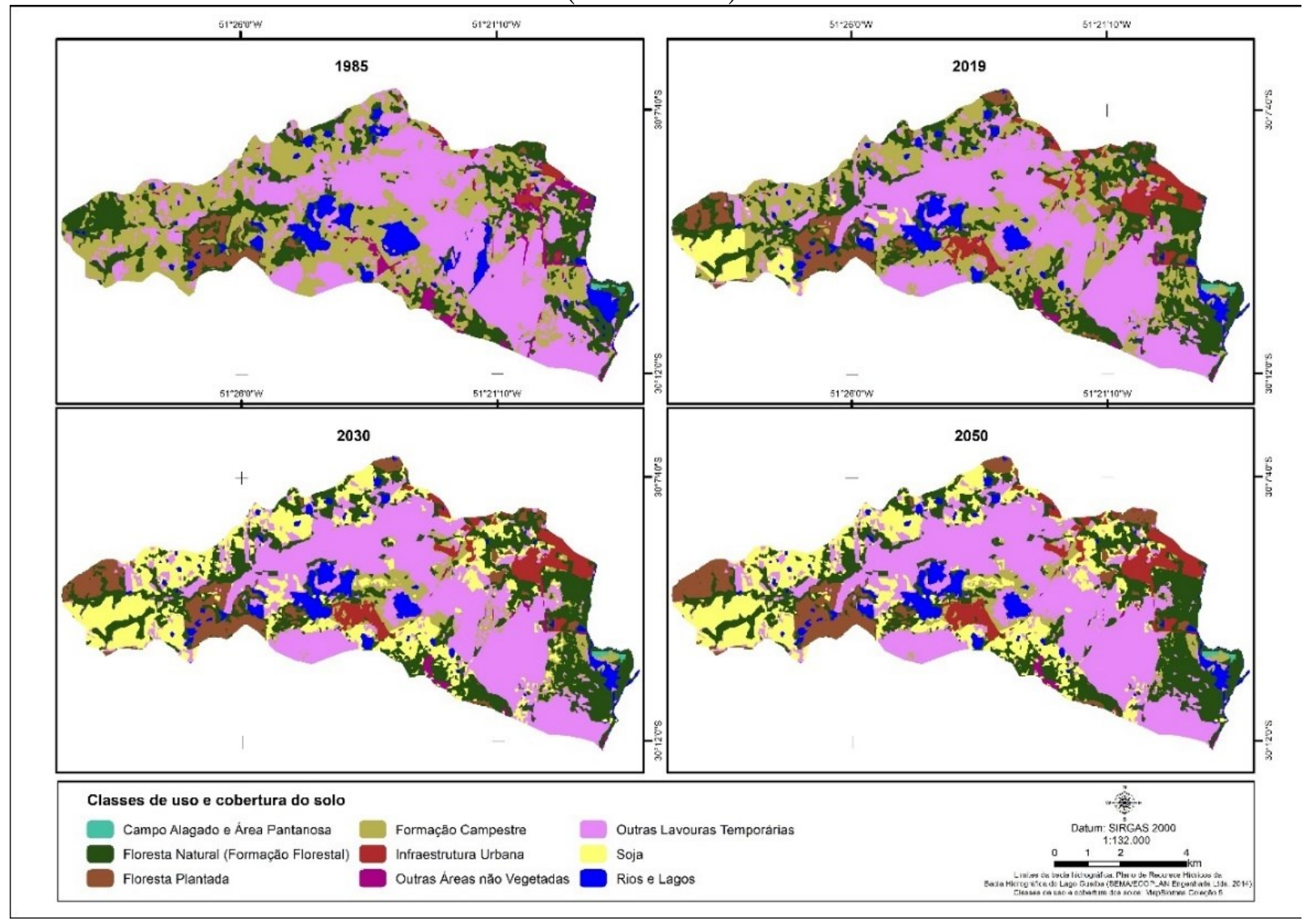

Fonte: Elaborado pelos autores (2021).

As transformações observadas de 1985 a 2019 (Figura 5) evidenciam que as áreas ocupadas pela classe Outras lavouras temporárias (excetuando-se a soja) foram predominantes, cobrindo $26,47 \mathrm{~km}^{2}(34,97 \%)$ da área em 1985 e $25,70 \mathrm{~km}^{2}(33,94 \%)$ em 2019 , com retração de $-1,03 \%$ no período.

A classe Formação Campestre ocupou segunda colocação em 1985, cobrindo $24,51 \mathrm{~km}^{2}$ $(32,38 \%)$ da área da sub-bacia e, ainda que tenha garantido a terceira maior colocação em termos de ocupação em 2019 (23,16\%), sofreu redução de $-6,98 \mathrm{~km}^{2}(-9,21 \%)$ no período, cedendo espaço principalmente para as classes Soja e Outras Lavouras Temporárias.

A classe Floresta Natural avançou $2,86 \mathrm{~km}^{2}$ $(3,77 \%)$ no período, ocupando $15,25 \mathrm{~km}^{2}$ $(20,14 \%)$ em 1985 e $18,10 \mathrm{~km}^{2}(23,91 \%)$ em 2019. Esta formação é composta por vegetação com predomínio de espécies arbóreas, mas não necessariamente representam áreas preservadas ou com vegetação nativa. Os dados levantados pelo Projeto MapBiomas apontaram que pelo menos $9,3 \%$ de toda a vegetação natural do Brasil é secundária, ou seja, são áreas que já foram desmatadas e convertidas para uso antrópico pelo menos uma vez (MAPBIOMAS,
2020). Pelo grau de antropização existente na sub-bacia, infere-se que a classe Floresta Natural seja composta por vegetação secundária.

Ainda que o crescimento desta classe tenha sido pequeno, ele foi superior ao avanço da Floresta Plantada, que ocupou $1,92 \mathrm{~km}^{2}(2,53 \%)$ em 1985 e $3,91 \mathrm{~km}^{2}(5,16 \%)$ da área total da subbacia em 2019, um aumento de 2,63\% no período. Na porção oeste da sub-bacia fica mais evidente o avanço da Floresta Plantada, onde a silvicultura se faz presente na área de plantio conhecida como Horto do Lagoão (Figura 1), pertencente a uma das maiores indústrias de celulose, papel e produtos de papel do estado (RIO GRANDE DO SUL, 2019). Este crescimento na SBAPF foi relativamente moderado em comparação às florestas plantadas no Bioma Pampa, que cresceram 4,9 vezes no mesmo período (MAPBIOMAS, 2020).

A partir de 2013 a classe Soja irrompeu em áreas na porção oeste da sub-bacia, antes destinadas a Outras Lavouras Temporárias e Formação Campestre, e em 2019 ocupou 2,75 $\mathrm{km}^{2}(3,64 \%)$ da área da sub-bacia. 
Figura 5 - Distribuição das classes de uso e cobertura do solo segundo o MapBiomas para os anos 1985 e 2019 e cenário tendencial 2030 e 2050.

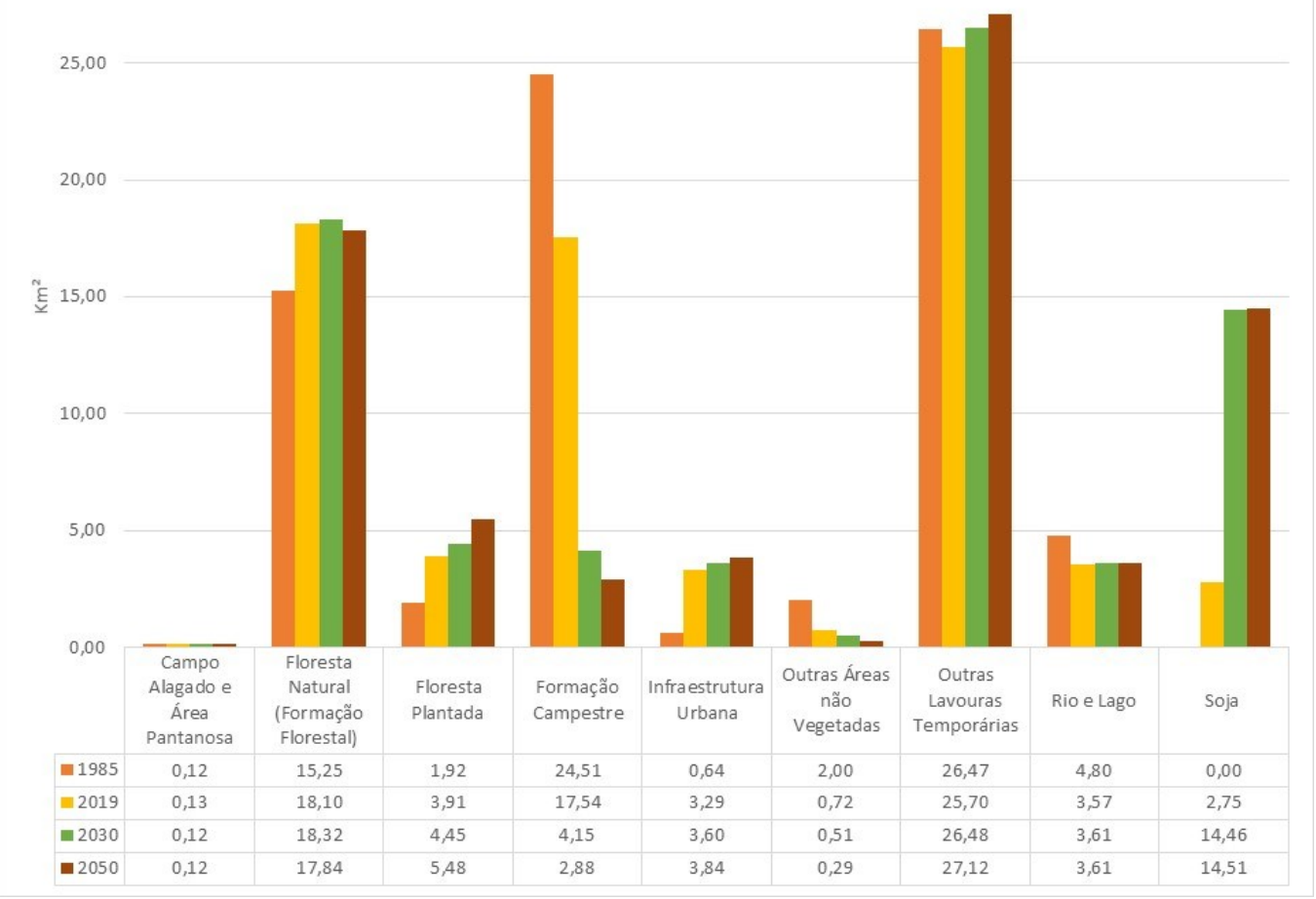

Fonte: Elaborado pelos autores (2021).

A classe Infraestrutura Urbana apresentou expansão significativa: em 1985 ocupava 0,64 $\mathrm{km}^{2}$ da área total da sub-bacia, passando a ocupar uma área de $3,29 \mathrm{~km}^{2}$ em 2019 , aumento observado especialmente na parte nordeste da SBHAPF (bairros Florida e Passo Fundo), que é uma área contígua à sede do município de Guaíba, e na porção centro-sul (bairro Pedras Brancas).

Em relação ao cenário tendencial, a classe Outras Lavouras Temporárias seguiu predominante, cobrindo $26,48 \mathrm{~km}^{2}$ em 2030 e $27,12 \mathrm{~km}^{2}$ em 2050.

A expansão mais significativa corresponde a conversão de áreas de Formação Campestre para áreas destinadas à classe Soja. Em 2019, a Formação Campestre ocupou $17,54 \mathrm{~km}^{2}$ da área da sub-bacia $(23,16 \%)$, e para 2030 e 2050 o cenário tendencial mostrou uma diminuição dessa classe, para $4,15 \mathrm{~km}^{2}$ e $2,88 \mathrm{~km}^{2}$, respectivamente, correspondendo a uma retração de $-14,65 \%$ de 2019 a 2050. Em contrapartida, a classe Soja, que ocupou 2,75 $\mathrm{km}^{2}$ em 2019, apresentou no cenário tendencial uma expansão considerável, saltando para 14,46 $\mathrm{km}^{2}(19,10 \%)$ em 2030 e $14,51 \mathrm{~km}^{2}(19,17 \%)$ em 2050 , um aumento de $11,76 \%$ da área total da sub-bacia entre 2019 a 2050.

O cenário tendencial também apontou expansão da classe Floresta Plantada, que passaria de $3,91 \mathrm{~km}^{2}$ em 2019 para $4,45 \mathrm{~km}^{2}$ em 2030 e $5,48 \mathrm{~km}^{2}$ em 2050, uma expansão de $1,58 \%$ entre 2019 e 2050. Pelo cenário tendencial esse aumento ocorreria sobre áreas de Floresta Natural.

Ainda que a área da classe Infraestrutura Urbana tenha aumentado $3,5 \%$ entre 1985 a 2019, o cenário tendencial mostrou uma expansão moderada, passando de uma ocupação de $4,35 \%$ em 2019 para 5,07\% em 2050, um aumento de $0,55 \%$.

\section{Avaliação dos serviços ecossistêmicos na SBHAPF}

Os SE na SBHAPF foram avaliados com base nos valores propostos inicialmente por Costanza et al. (1997), considerando-se os totais em área por hectare para as classes de uso e cobertura do solo do Projeto MapBiomas observados em 1985 e 2019 e projetados para 2030 e 2050 na subbacia. Os SE foram correlacionados a essas classes, obtendo-se o valor por tipo de serviço, o total por classe de uso e cobertura do solo e o valor total em dólares americanos (US\$) atualizados conforme a taxa de inflação para aquele país no ano de 2020, (Tabela 2). 
Tabela 2 - Valor global médio anual dos serviços ecossistêmicos para a SBHAPF (1985, 2019 e 2050).

Serviços Ecossistêmicos (valor em US\$ para o ano 2020*, ha/ano) (adaptado de COSTANZA et al., 1997)

Área na SBHAPF

(ha)

Valor total (total SE x área em
ha)
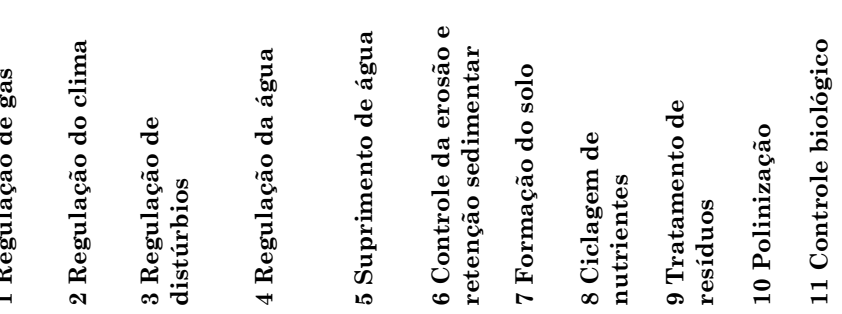

$\begin{array}{lll}18.390 & 76 & 19.304\end{array}$

4.214

Campo Ala
Pantanosa

Floresta Natural

Floresta Plantada

Formação Campestre

Infraestrutura Urbana

Outras Áreas não

Vegetadas

Outras Lavouras

Temporárias

Soja

Rios e Lagos

Total $\begin{array}{lll}36 & 61 & 137\end{array}$

1.689 $\begin{array}{lll}1.115 & 119 & 124\end{array}$

1.247

$\begin{array}{llll}81 & 800 & 104 & 284\end{array}$

$127 \quad 64$

170

$\begin{array}{lll}221 & & 10 \\ 221 & 64 & 58\end{array}$

म.473 49.736

9.736

12

91

$\begin{array}{lr}5 & 5.100 \\ 5 & 767\end{array}$

$\begin{array}{rrrrrrr}767 & 192 & 391 & 548 & 147.279 & 299.928 & 420.360 \\ 620 & 2.451 & 1.754 & 288 & 1.519 .032 & 1.087 .059 & 178.491\end{array}$

*A taxa de inflação nos Estados Unidos entre 1984 e 2020 foi de 154,01\%, o que se traduz em um aumento total de US $\$ 1,54$. Isso sionifica que 1 dólar em 1984 equivale a 2,54 dólares em 2020. Em outras palavras, o poder de compra de $\$ 1$ em 1984 é igual a $\$ 2,54$ hoje. A taxa média de inflação anual foi de 2,55\%. Fonte: Inflation Tool (2020). As células sombreadas indicam os serviços que não ocorrem ou são considerados insignificantes. Células em branco indicam falta de informação disponível. 
Os resultados indicaram que a SBHAPF forneceu em torno de US\$21.020.441 em SE em 1985. A maior parte dos serviços ecossistêmicos foi fornecida pela classe Rios e lagos (US\$ 10.360.762), sendo o principal a Regulação da água (Figura 6), que em 1985 correspondia a
US\$ 6.638.544. A função deste serviço concentra-se na regulação dos fluxos hidrológicos, fundamentais para a provisão de água para a agricultura, os processos industriais e o abastecimento da área urbana na sub-bacia.

Figura 6 - Distribuição dos SE (US\$/ha/ano) na classe Rios e Lagos.

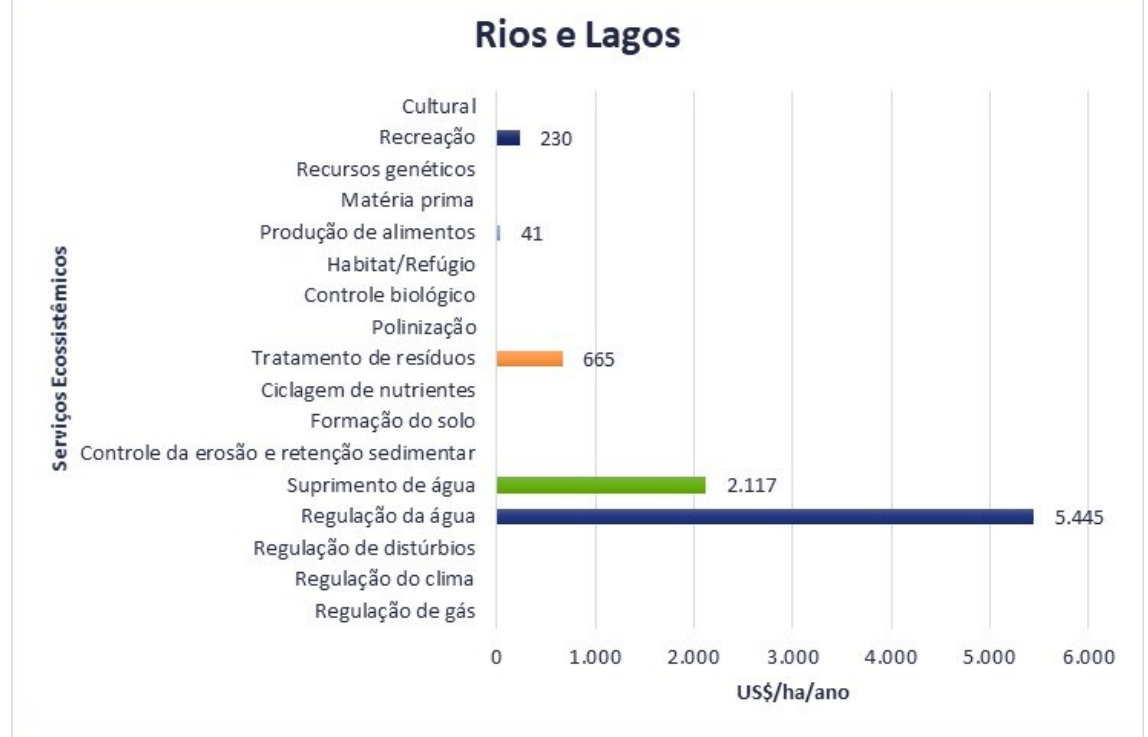

Fonte: Elaborado pelos autores (2021).

Ainda na classe Rios e lagos, o SE Suprimento de água também teve destaque na sub-bacia $(24,91 \%)$, pois qualquer alteração em seu funcionamento impacta diretamente as condições do Arroio Passo Fundo, acentuando ou minimizando os problemas associados à qualidade deste corpo hídrico. Este SE forneceu US\$2.581.046 em 1985, com queda para US\$ 1.919 .653 em 2019. O cenário tendencial projetado para 2050 prevê aumento na área da classe Rios e lagos, levando ao incremento dos valores para este período.

A classe Rios e lagos desempenha papel importante também no serviço de Recreação. Ainda que o mapeamento dos SE contemple somente as áreas dentro dos limites da subbacia em análise, os serviços de recreação e culturais (incluindo também aspectos religiosos e de apreciação da paisagem) estão fortemente relacionados aos usos e aos vínculos existentes entre a população local e visitantes e o Lago Guaíba.

As classes caracterizadas por florestas fornecem uma variedade de SE, como manutenção da estabilidade geofísica do terreno, redução da erosão dos solos e purificação do ar. As árvores são importantes nos processos de armazenamento de água, desempenhando um papel crítico na evapotranspiração, além de fornecer caminhos para retenção de água em reservatórios subsuperficiais. Como resultado, obtém-se um fluxo de água constante a jusante, redução nos eventos de inundação e um estoque médio maior de abastecimento de água disponível. As florestas também oferecem serviços de regulação do clima em escala local e global. Chuvas locais podem ser reduzidas como resultado do desmatamento, uma vez que o armazenamento de água e a evapotranspiração são diminuídos. As florestas também promovem valores associados à manutenção de espécies e diversidade genética (COSTANZA et al., 1998).

A classe Floresta Natural forneceu valor correspondente a US\$ 7.777.988 em 1985, US\$ 9.231.579 em 2019 e US\$ 9.098.971 no cenário tendencial de 2050. A variação no valor entre 1985 a 2019 foi de $0,19 \%$, e entre 2019 para 2050 houve queda de - $0,01 \%$. Dentro dessa classe, a Ciclagem de nutrientes foi o SE preponderante (Figura 7), destacou-se também o fornecimento de Matéria-prima, o Controle da erosão e retenção sedimentar e a Regulação do clima 
Figura 7 - Distribuição dos SE (US\$/ha/ano) na classe Floresta Natural.

\section{Floresta Natural (Formação Florestal)}

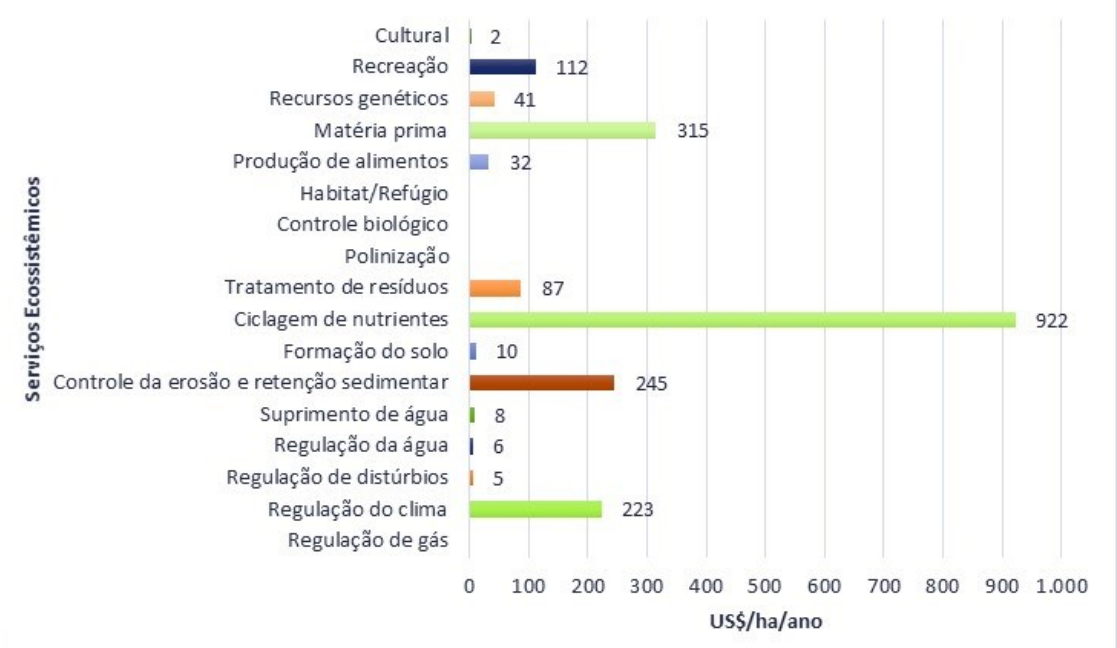

Fonte: Elaborado pelos autores (2021).

Já o valor da classe Floresta Plantada cresceu $1,04 \%$ no período compreendido entre 1985 a 2019, e entre 2019 a 2050 prevê-se que tenha crescimento de $0,40 \%$, passando de US\$ 299.928 para US $\$$ 420.360. Comparando-se a
Floresta Natural e a Floresta Plantada, observase que, a segunda fornece menor quantidade de tipos de SE e, consequentemente, menor valor por área em termos gerais (Figura 8).

Figura 8 - Distribuição dos SE (US $\$ /$ ha/ano) na classe Floresta Plantada.

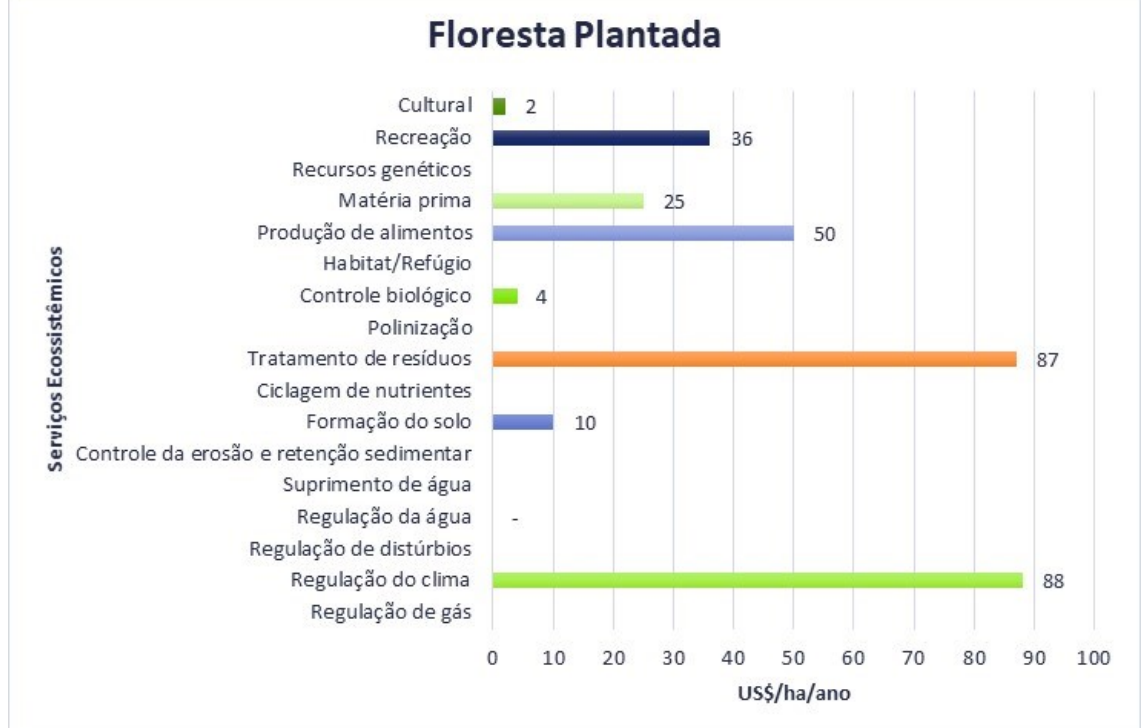

Fonte: Elaborado pelos autores (2021).

Serviços como Regulação de distúrbios, Regulação e Suprimento de água, Controle da erosão e retenção sedimentar, Ciclagem de nutrientes e Recursos genéticos não são fornecidos pela classe Floresta Plantada em comparação com a Floresta Natural. Em contrapartida, há maior oferta de Controle Biológico e Produção de alimentos. Quanto ao SE Matéria prima, a Floresta Plantada fornece madeira para indústria moveleira, celulose, papel, carvão vegetal e biomassa, e o mercado tem investido em novas tecnologias para aproveitamento total da floresta.

Ainda que dentro da SBHAPF a classe Campo alagado e área pantanosa tenha oscilado entre 12 e 13 ha nos anos observados, é notória a importância em termos de valores da produção dos SE totais por hectare, que correspondeu a US\$ 49.736 . 
A classe Formação Campestre apresentou as maiores perdas no período, passando de 2.451 ha em 1985 para 1.754 ha em 2019, com queda ainda maior para o cenário tendencial de 2050, correspondente a 288 ha. A diminuição em área desta classe se reflete consequentemente na redução dos SE oferecidos. A Formação Campestre é composta por vegetação com predomínio de estrato herbáceo graminoide, fortemente associada à paisagem do Bioma Pampa. Essa diminuição representa uma variação de $-0,28 \%$ entre 1985 a 2019 no fornecimento de serviços ecossistêmicos, o qual representa -US\$ 431.973, e no cenário tendencial essa retração é ainda maior, com queda de - $0,84 \%$ entre 2019 a 2050 , que equivale a -US\$ 908.568.

A classe Formação Campestre tem a maior parte dos seus serviços concentrados no Tratamento de resíduos (Figura 9), cuja função ecossistêmica principal consiste em recuperar nutrientes móveis e remover ou decompor excesso de nutrientes.

Figura 9 - Distribuição dos SE (US\$/ha/ano) na classe Formação Campestre.

\section{Formação Campestre}

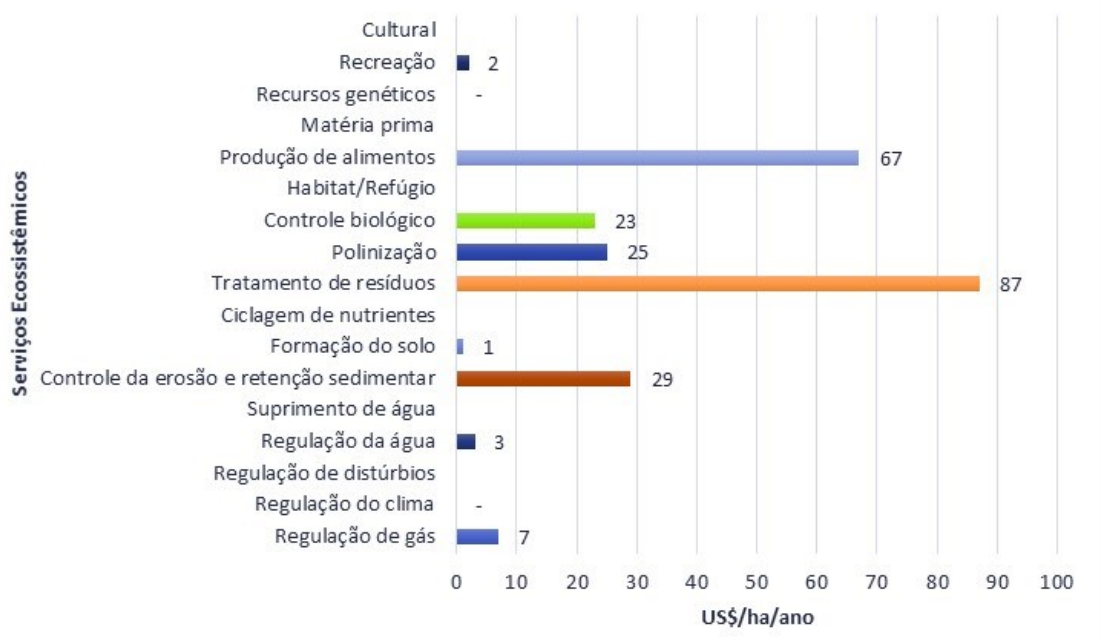

Fonte: Elaborado pelos autores (2021).

Também se destaca a classe Produção de alimentos, que tem como função a produção primária bruta extraída como alimento e corresponde na sub-bacia à produção de cultivos e agricultura de subsistência. A Formação Campestre é a principal classe fornecedora do SE Polinização, provendo polinizadores para produção de populações de plantas.

\section{CONSIDERAÇÕES FINAIS}

Este estudo avaliou as transições ocorridas nas classes de uso e cobertura do solo na sub-bacia hidrográfica do Arroio Passo Fundo entre os anos de 1985 a 2019, com projeção do cenário tendencial para 2030 e 2050 , correlacionando cada classe com os Serviços Ecossistêmicos propostos pela classificação de Costanza et al. (1998). Esta avaliação em termos de quantidade de área e tipos de SE é uma abordagem em expansão em muitos países, mas ainda pouco empregada no Brasil.
A proposta de valores atribuídos a cada SE não tem pretensão de ser incontestável ou absoluta, visto que os mesmos não são globalmente homogêneos, mas são uma aproximação que permite medir os serviços no tempo e no espaço, e tem como objetivo orientar a elaboração de políticas públicas, incentivos e tecnologias que estimulem uma melhor gestão dos benefícios que as pessoas obtêm do funcionamento dos ecossistemas. Atribuir valores ao serviço prestado não significa precificar a natureza ou colocá-la à venda em mercados destinados a este fim, mas trata de trazer um significado e evidenciar a importância de cada serviço fornecido para fins de monitoramento e perda desse benefício que parece estar à disposição de forma ilimitada.

As limitações da escala de mapeamento do Projeto MapBiomas não permitem uma averiguação com detalhe acurado da sub-bacia, mas foram suficientes para uma avaliação ambiental, considerando-se que os dados são gratuitos, de fácil acesso e disponíveis para qualquer gestor público ou analista ambiental, o 
que permite fazer uma avaliação ao longo do tempo e traçar metas que podem ser monitoradas através do indicador de alteração das classes de uso e ocupação do solo. O recorte espacial pode ser tanto uma bacia hidrográfica como outro limite administrativo.

Outra limitação inerente ao método é a exclusão do Lago Guaíba como parte da subbacia, visto que têm importância ímpar nos SE de Recreação e Cultural. Estes serviços são contemplados de forma parcial na classe Rios e Lagos e Floresta Natural, que são adjacentes à orla, mas em tese teriam que ser muito melhor valorados pelas relações existentes entre a população local e os benefícios oferecidos pelo lago.

De maneira geral, a SBHAPF possui aptidão para o uso agrícola, visto que as maiores ocupações ocorreram nas categorias Outras lavouras temporárias, Floresta Natural e, mais recentemente, a intensa ocupação pelas lavouras de soja. Como pode ser observado nos resultados, a alteração mais significativa corresponde à conversão de áreas de Formação Campestre para áreas destinadas à classe Soja, ressaltando-se que a primeira abriga todos os elementos que particularizam o pampa na região.

A área da classe Floresta plantada aumentou no período considerado, bem como a Floresta natural. A silvicultura tem presença marcante na região e correntemente é alvo de conflitos, mas os dados avaliados na área de estudo evidenciam que o aumento da classe Floresta plantada não está avançando necessariamente sobre a Floresta natural. Há uma tendência de que as Florestas plantadas acarretem diminuição da pressão sobre as Florestas naturais, com o avanço de tecnologias e eficiência de manejo. A metodologia proposta não avalia a polinização na classe Floresta plantada, mas é de conhecimento público que a principal empresa responsável pela silvicultura na sub-bacia realiza trabalho com apicultores que colocam suas colmeias sem nenhum custo junto aos plantios de eucalipto.

O problema mais urgente da SBHAPF está relacionado à diminuição da qualidade de água, consequência da falta de saneamento, despejos industriais inadequados e expansão urbana desordenada próximos a área a jusante do arroio Passo Fundo, o que leva a perda gradativa de SE como a Regulação e suprimento de água, Tratamento de resíduos e Recreação. Estes serviços devem receber atenção especial e os ecossistemas degradados devem ser reabilitados, através da proteção da mata ciliar, implantação de saneamento básico para a totalidade da população e medidas de fiscalização mais efetivas por parte dos órgãos públicos para atividade industrial poluidora. Essas ações precisam ser consideradas no futuro, pois devem trazer como resposta aumento do capital natural e dos SE na subbacia, e podem ser medidos e monitorados através da classificação disponibilizada pelo Projeto MapBiomas.

Ainda que existam muitas formas de monitoramento e diferentes indicadores de avaliação, os SE apontam uma solução de fácil acesso e utilização, que pode ser utilizada sem custos por parte de gestores públicos, permitindo que alguma iniciativa seja tomada de forma imediata, sem deixar a situação se agravar ou ficar estagnada.

Por fim, observa-se que o cenário tendencial não significa uma predição absoluta do futuro para os anos previstos, mas trazem uma representação de uma condição provável se medidas adequadas não forem tomadas. Para esta avaliação, faz-se necessária a inclusão de condutores de mudança para avaliação de diferentes cenários.

\section{AGRADECIMENTOS}

O presente trabalho foi realizado com apoio da Coordenação de Aperfeiçoamento de Pessoal de Nível Superior - Brasil (CAPES) - Código de Financiamento 001.

\section{REFERÊNCIAS}

BACHI, L. et al. Cultural Ecosystem Services (CES) in landscapes with a tourist vocation: Mapping and modeling the physical landscape components that bring benefits to people in a mountain tourist destination in southeastern Brazil. Tourism Management, [s. 1.], v. 77, n. May 2020 . https://doi.org/10.1016/j.tourman.2019.104017

BAGSTAD, K. J.; SEMMENS, D. J.; WINTHROP, R. Comparing approaches to spatially explicit ecosystem service modeling: A case study from the San Pedro River, Arizona. Ecosystem Services, [s. 1.], v. 5, p. 40-50, 2013. https://doi.org/10.1016/j.ecoser.2013.07.007

CABRAL, P. et al. Assessing the impact of landcover changes on ecosystem services: A first step toward integrative planning in Bordeaux, France. Ecosystem Services, [s. 1.], 2016. https://doi.org/10.1016/j.ecoser.2016.08.005 
COSTANZA, R. Nature: ecosystems without commodifying them. Nature, [s. 1.], v. 443, n. 7113, p. 749, 2006 . https://doi.org/10.1038/443749b

COSTANZA, R. et al. The value of the world's ecosystem services and natural capital. Ecological Economics, [s. 1.], v. 25, n. 1, p. 3-15, 1998. https://doi.org/10.1016/S09218009(98)00020-2

COSTANZA, R. et al. Twenty years of ecosystem services: How far have we come and how far do we still need to go? Ecosystem Services, [s. l.], v. 28, p. 1-16, 2017. https://doi.org/10.1016/j.ecoser.2017.09.008.

COSTANZA, R., D'ARGE, R., DE GROOT, R. et al. The value of the world's ecosystem services and natural capital. Nature 387, 253260.1997. https://doi.org/10.1038/387253a0

DAILY, G. C. Nature's Services: Societal Dependence on Natural Ecosystems. Island Preed. Washington D.C.: [s. n.], 1997.

DE LIMA, A. D. S. et al. Ecosystem-based information as a support tool to the integrated coastal management of the Santa Catarina Island, Brazil. Desenvolvimento e Meio Ambiente, [s. 1.], v. 44, p. 20-35, 2018. https://doi.org/10.5380/dma.v44i0.54947

DINAMICA EGO. Centro de Sensoriamento Remoto / Universidade Federal de Minas Gerais - Brasil. 2020. Disponível em: https://csr.ufmg.br/dinamica/. Acesso em: 01 set 2020 .

DRH/SEMA. Departamento de Recursos Hídricos da Secretaria de Estado do Meio Ambiente do Rio Grande do Sul. Plano da Bacia Hidrográfica do Lago Guaíba. Relatório Final Síntese e SIG - Revisão 01. 2016. Disponível em: http://comitedolagoguaiba.com.br/wpcontent/uploads/2017/08/Relat\%C3\%B3rio_Fi nal_Sintese_Rev01_completo-comp.pdf.

Acesso em: 01 fev 2019.

GUERRA, T. et al. Diagnóstico Ambiental da bacia hidrográfica do arroio Passo Fundo, município de Guaíba, RS. Porto Alegre, p. 111, 2002. Disponível em: http://www.ecologia.ufrgs.br/lagoguaiba/event os/MostraTrabalhos/trabalhos/21

arroio\%20\%20passo\%20fundo.pdf. Acesso em: 22 out. 2019.

HERNÁNDEZ-BLANCO, M. et al. Future scenarios for the value of ecosystem services in Latin America and the Caribbean to 2050. Current Research in Environmental Sustainability, [s. l.], v. 2, p. 100008, 2020. https://doi.org/10.1016/j.crsust.2020.100008

INFLATION TOOL. Value of 1984 US Dollars today. 2020. Disponível em: https://www.inflationtool.com/us-dollar/1984- to-present-value?amount=1. Acesso em: $01 \mathrm{dez}$ 2020.

KUBISZEWSKI, I. et al. The future value of ecosystem services: Global scenarios and national implications. Ecosystem Services, [s. 1.], v. 26, p. 289-301, 2017. https://doi.org/10.1016/j.ecoser.2017.05.004

LEITÃO, L. C. R.; SANTOS, J. G. dos; ARAGÃO, M. A. de S. Mapeamento e Avaliação de Serviços dos Ecossistemas do sitio de Importância Comunitária "Dunas De Mira, Gândara e Gafanhas". IV Simpósio Brasileiro de Geomática - II Jornadas Lusófonas - Ciências e tecnologias de Informação Geográfica. Presidente PrudenteSP: $\quad$ [s. n.], 2017. https://doi.org/10.22533/at.ed.1111928036

MAES, J. et al. Mapping and assessment of ecosystems and their services: An analytical framework for ecosystem assessments under Action 5 of the EU Biodiversity Strategy to 2020. [S. l.: s. n.], 2013. https://doi.org/10.2779/12398

MAES, J. et al. Mapping ecosystem services for policy support and decision making in the European Union. Ecosystem Services, [s. 1.], v. $1, \quad$ n. $1, \quad$ p. $31-39,2012$. https://doi.org/10.1016/j.ecoser.2012.06.004

MARTINEZ-HARMS, M. J. et al. Scenarios for land use and ecosystem services under global change. Ecosystem Services, [s. 1.], v. 25, p. 56-68, 2017. https://doi.org/10.1016/j.ecoser.2017.03.021

MEA. Millennium Ecosystem Assessment. Ecosystems and Human Well-being: Synthesis. Washington, DC: [s. n.], 2005. Disponível em: http://www.millenniumassessment.org/en/Syn thesis.aspx . Acesso em: 02 mar. 2020.

PROJETO MAPBIOMAS - Coleção 5 (19852019) da Série Anual de Mapas de Cobertura e Uso de Solo do Brasil. 2020. Disponível em: <https://plataforma.mapbiomas.org/map\#cove rage $>$. Acesso em: 01 set 2020.

RIO GRANDE DO SUL. Atlas Socioeconômico Rio Grande do Sul. Secretaria de Planejamento, Orçamento e Gestão. Departamento de Planejamento Governamental. 4 ed. Porto Alegre: Secretaria de Planejamento, Orçamento e Gestão, 2019. 125 p. Disponível em: https://atlassocioeconomico.rs.gov.br/inicial Acesso em 15 jan 2021.

ROCHA, J. (2012). Sistemas complexos, modelação e geosimulação da evolução de padrões de uso e ocupação do solo. Tese de doutorado, Geografia (Ciências da Informação Geográfica), Universidade de Lisboa, Instituto 
de Geografia e Ordenamento do Território, $2012 . \quad$ Disponível em: http://hdl.handle.net/10451/6772 . Acesso em: 20 jan 2021.

RODRIGUES, H. O.; SOARES-FILHO, B. S.; COSTA, W. L. de S. Dinamica EGO, uma plataforma para modelagem de sistemas ambientais. Anais XIII Simpósio Brasileiro de Sensoriamento Remoto, Florianópolis, Brasil, 21-26 abril 2007, INPE, p. 3089-3096. Disponível

em: https://www.researchgate.net/publication/228 624479_Dinamica_EGO_uma_plataforma_par a_modelagem_de_sistemas_ambientais Acesso em: 22 nov. 2020.

SOARES-FILHO, B. S.; ARAÚJO, A. A.; CERQUEIRA, G. C. DINAMICA - Um software para simulação de dinâmica de paisagens. II Workshop Tratamento de imagens, [s. 1.], p. 3, 2001. Disponível em: http://www.dpi.inpe.br/cursos/tutoriais/model agem/software_demos/Dinamica/soares.pdf Acesso em: 22

nov. 2020.

SOARES-FILHO, B. S.; RODRIGUES, H. O.; COSTA, W. L. Modeling environmental dynamics with Dinamica EGO. Instituto de Geociências - Centro de Sensoriamento Remoto, [s. 1.], n. October, p. 114, 2009. Disponível em: https://www.researchgate.net/profile/Tao_Guo 28/publication/282782423_Dinamica_EGO_gu idebookpdf/links/561c711108aea80367243fdc. pdf Acesso em: 14 jul. 2020.

WOLDEYOHANNES, A.; COTTER, M.; BIRU, W.D.; KELBORO, G. Assessing Changes in Ecosystem Service Values over 1985-2050 in Response to Land Use and Land Cover Dynamics in Abaya-Chamo Basin, Southern Ethiopia. Land, [s. 1.], v. 9, p. 37, 2020. https://doi.org/10.3390/land9020037

\section{CONTRIBUIÇÃO DOS AUTORES}

Sumirê da Silva Hinata concebeu o estudo, coletou, analisou os dados e redigiu o texto. Luis Alberto Basso orientou, analisou os dados e redigiu o texto. José Gomes dos Santos analisou os dados e redigiu o texto. 